\title{
Three years of pulmonary rehabilitation: inhibit the decline in airflow obstruction, improves exercise endurance time, and body-mass index, in chronic obstructive pulmonary disease David Stav*1,2, Meir Raz ${ }^{3}$ and Isaac Shpirer ${ }^{1}$
}

\author{
Address: ${ }^{1}$ Pulmonary Institute, Tel Aviv University, Assaf Harofeh Medical Center, Zerrifin, Israel, ${ }^{2}$ Tel Aviv Lung Association, Tel Aviv, Israel and \\ ${ }^{3}$ Maccabi Health Services, Tel Aviv, Israel \\ Email: David Stav* - dstav@asaf.health.gov.il; Meir Raz - raz_m@maccabi.org.il; Isaac Shpirer - i_shpirer@yahoo.com \\ * Corresponding author
}

Published: 30 May 2009

BMC Pulmonary Medicine 2009, 9:26 doi:10.1 I86/147/-2466-9-26

This article is available from: http://www.biomedcentral.com/I47I-2466/9/26

(c) 2009 Stav et al; licensee BioMed Central Ltd.

This is an Open Access article distributed under the terms of the Creative Commons Attribution License (http://creativecommons.org/licenses/by/2.0), which permits unrestricted use, distribution, and reproduction in any medium, provided the original work is properly cited.
Received: 16 October 2008

Accepted: 30 May 2009

\begin{abstract}
Background: Pulmonary rehabilitation is known to be a beneficial treatment for COPD patients. To date, however, there is no agreement for how long a rehabilitation program should be implemented. In addition, current views are that pulmonary rehabilitation does not improve FEV, or even slow its decline in COPD patients. The aim of the study was to examine the efficacy of a 3 year outpatient pulmonary rehabilitation (PR) program for COPD patients on pulmonary function, exercise capability, and body mass index (BMI).

Methods: A matched controlled trial was performed with outcome assessments evaluated at 6 , $12,18,24,30$, and 36 months. Eighty patients with moderate to severe COPD (age $63 \pm 7$ years; $\mathrm{FEV}, 48 \% \pm 14$ ) were recruited. The control group received standard care only, while in addition, the case study group received PR for duration of three years. These groups were matched for age, sex, BMI, $\mathrm{FEV}, \%$ and number of pack-years smoked.

Results: The decline in FEV after the three years was significantly lower in the PR group compared to control, $74 \mathrm{ml}$ versus $149 \mathrm{ml}$, respectively $(p<0.00 \mathrm{I}$ ). Maximal sustained work and endurance time improved after a short period of PR and was maintained throughout the study, in contrast to the control group $(p<0.01)$. A decreased BMI was noted in the control group after three years, while in the PR group a mild improvement was seen $(p<0.05)$.
\end{abstract}

Conclusion: Three years of outpatient pulmonary rehabilitation resulted in modifying the disease progression of COPD, as well as improving physical performance in these patients.

\section{Background}

Chronic obstructive pulmonary disease (COPD) is a chronic progressive respiratory disorder causing disability with an increasing burden to the patient, his family and to the health services. Ppatients with COPD commonly experience reduced exercise capacity and activity limitation. Furthermore, exercise intolerance is a major determi- nant of impaired quality of life for COPD patients, and improvement in exercise capacity is a key goal of COPD disease management [1].

Drug treatment regimens provides only partial benefit, and many patients remain symptomatic with impaired exercise capacity and and a worsening quality of life. For 
example, prospective studies testing for the effects of inhaled short-acting anticholinergic drugs, inhaled corticosteroids, or $\mathrm{N}$-acetylcysteine on the progression of chronic obstructive pulmonary disease (COPD) failed to demonstrate a change in the slope of the forced expiratory volume in 1 second $\left(\mathrm{FEV}_{1}\right)$ in these patients [2-4]. To date, only smoking cessation has prospectively been shown to alter the rate of decline of $\mathrm{FEV}_{1}$ in patients with COPD [5]. Pulmonary rehabilitation (PR) is used as a complementary treatment option for these patients, Recently, the American Thoracic Society (ATS) and the European Thoracic Society (ERS) published a statement, in which PR was recognized as an evidence-based, multidisciplinary, and comprehensive intervention for patients with chronic respiratory diseases who are symptomatic and often have decreased daily life activities. [6]. This statement was followed by a position paper by the ACCP/AACVPR that support and enhance the previously described statement [7]. One of the major unresolved issues is the duration of treatment. For example, outpatient exercise training with two or three weekly sessions for 4 weeks showed less benefit than similar training for 7 weeks [8-10].

In order to evaluate the efficacy of pulmonary rehabilitation to alter the course of disease in COPD, we carried out in an outpatient setting, a controlled trial comparing 36 months of PR along with standard care and to the effects of standard care without rehabilitation. The outcome measurements included changes in the rate of $\mathrm{FEV}_{1}$ decline, its effects on exercise endurance and the change of body mass index (BMI).

\section{Methods}

COPD patients who were on long acting beta agonist (LABA) or combined inhalers of corticosteroids and LABA, were matched for age, sex, BMI, $\mathrm{FEV}_{1} \%$ and number of pack-years smoked into two groups, those receiving pulmonary rehabilitation in addition to standard care and a control group receiving inhaled drugs as described above [11]. Patients were eligible for inclusion if they were younger than 70 years of age, had a $\mathrm{FEV}_{1}$ that was less than $60 \%$ and higher than $30 \%$, of predicted value and their improvement after bronchodilator inhalation (400 $\mu$ g salbutamol) was less than $12 \%$. In addition, their clinical condition had been stable for at least 2 months prior to enrollment. We excluded patients who were active smokers or had quit smoking less than 2 years prior to the onset of this study and those in whom there were other severe medical problems such as heart failure, myocardial infarction, cerebrovascular disease, cancer, or severe orthopedic disorders.

PR was carried out in groups of 6-8 patients, twice a week during the course of the study. Each session consisted of exercises of both upper and lower extremities as well as integrated physical activity. This program was directed by an exercise therapist. Patients were instructed to carry out exercises at home simulating what they did in the groups, on at least two additional days per week. In addition, meetings on an individual basis with a psychologist, sometimes with family members included, occurred as needed. The patients were seen initially by the supervising physician and at intervals of three months for routine follow up and for functional evaluations. In addition, physician encounters occurred as needed. The control group was similarly seen and assessed by a pulmonary physician at three months intervals, in addition to as needed.

Pulmonary function studies were carried out at enrollment and at intervals throughout the study period. Spirometry (Medical Graphics, Inc., St. Paul, Minnesota) including $\mathrm{FEV}_{1}$ and forced vital capacity, were measured according to American Thoracic Society guidelines [12]. The BMI was re-calculated at every spirometry.

\section{Exercise Endurance}

During the run-in period, exercise tolerance was evaluated with a constant-load cycle ergometer on two separate visits. The constant-load tests were performed at $75 \%$ of the maximal work rate achieved during the incremental exercise test at screening. The purpose of the run-in exercise tests was to familiarize the study subjects with the constant-load exercise test procedures and reduce possible learning effects [13]. Cycle endurance time was defined as the duration of loaded pedaling. For the incremental test, the initial work rate was 10 Watts (W) and the work rate was increased by $10 \mathrm{~W}$ every minute until symptom limitation. Pulse oximetry, ECG, and BP were monitored at rest, during exercise, and at recovery.

\section{Statistical Analysis}

Data are presented as mean \pm SD. Analysis of variance (ANOVA) was used to compare between the groups for analysis of the entire 36 months period. For time point differences we used, a two-sample t test with a significance level of 0.05 .

\section{Study ethics}

The study was approved by the Tel Aviv Lung Association, Institutional Review Board

http://www.clinicaltrial.gov - TLA1948

\section{Results}

Eighty consecutive eligible patients fulfilled inclusion criteria and were matched to either the training group (40) or the control group (40). Thirteen patients, $16 \%$ (6 in the rehabilitation group and 7 in the control group) did not complete the 3 years of follow up (Table 1). All patients had moderate-severe COPD with moderate peripheral 
Table I: Base line characteristics of the study subjects

\begin{tabular}{|c|c|c|c|c|c|c|}
\hline & \multicolumn{3}{|c|}{ Control group } & \multicolumn{3}{|c|}{ Rehabilitation group } \\
\hline & Completed & Withdrawn & All & Completed & Withdrawn & All \\
\hline No. & 33 & 7 & 40 & 34 & 6 & 40 \\
\hline Age & $62 \pm 5.4$ & $64 \pm 2.8$ & $63.2 \pm 5$ & $63 \pm 5.2$ & 63.2 & $62.6 \pm 6$ \\
\hline Male & $70 \%$ & $76 \%$ & $72 \%$ & $72 \%$ & $75 \%$ & $75 \%$ \\
\hline BMI & $24.6 \pm 1.8$ & $24.2 \pm 1.4$ & $24 \pm 1.6$ & $24.2 \pm 1.9$ & $23.8 \pm 1.6$ & $24.1 \pm 1.7$ \\
\hline $\mathrm{FEV}, \%$ & $44 \pm 8$ & $46 \pm 7$ & $44 \pm 9$ & $47 \pm 5$ & $48 \pm 6$ & $47 \pm 8$ \\
\hline $\mathrm{FEV}_{1} / \mathrm{FVC}$ & $0.56 \pm 0.06$ & $0.54 \pm 0.04$ & $0.52 \pm 0.07$ & $0.56 \pm 0.08$ & $0.52 \pm 0.03$ & $0.54 \pm 0.06$ \\
\hline Pack year & $24 \pm 7$ & $27 \pm 4$ & $26 \pm 8$ & $27 \pm 6$ & $30 \pm 4$ & $28 \pm 10$ \\
\hline
\end{tabular}

BMI-body mass index, FEV \% \%-percent of predicted of forced expiratory volume in I second

and respiratory muscle weakness and impaired functional and maximal exercise capacity. There were no significant differences in the characteristics of the 80 patients who initially participated in the PR and control groups (Table 1).

The rate of $\mathrm{FEV}_{1}$ decline was measured after administration of a 400 ug of salbutamol, a short acting bronchodilator. Figure 1 depicts the changes in $\mathrm{FEV}_{1}$ over time in the pulmonary rehabilitation and control groups, and demonstrates a significant difference $(\mathrm{p}<0.001)$ between these two groups. In addition, the decline of $\mathrm{FEV}_{1}$ in the PR group was significantly lower when comparing each individual time point $(\mathrm{p}<0.05)$. In the PR group the $\mathrm{FEV}_{1}$ was reduced by $74 \mathrm{ml}$ during the 3 years study, whereas in the control group it was $149 \mathrm{ml}$. Table 2 demonstrates an immediate significant improvement $(\mathrm{p}<0.001)$ in exercise endurance time and work in the PR group, which was basically maintained during the study duration. In contrast, in the control group no significant differences was observed. BMI improvement in PR treated group was significant after more than 1 year, and an opposite change was observed in the control group.

\section{Discussion}

Our study demonstrates that a prolonged rehabilitation program inhibits the progression of airflow obstruction in COPD patients. In addition, it increased endurance time and work, and improved BMI. FEV $\mathrm{F}_{1}$ is used in COPD for disease staging and since it declines progressively, its value is a predictor of life expectancy. Various exercise tests, dif- ferent physiological parameters, and BMI are used as surrogates for clinical status assessment. Our study did not show that PR improved $\mathrm{FEV}_{1}$, which is in accordance to a previous report, but showed beneficial interference with its progressive decline.

Previous studies have shown some improvement in FVC which may have been due to improved respiratory muscle function and a reduction in small airways disease [3]. The improvement in $\mathrm{FEV}_{1}$ in those cases was small and not statistically significant. We noted a significant inhibtion of the progression of airways obstruction occurring after the three years of treatment, and thus we speculate that participating in the pulmonary rehabilitation program increased in incremental stages small airways function and/or recruitment. In addition, the exercise regimen likely improve secretions evacuation, which can reduce airways infections/inflammation and decrease COPD exacerbations. For example, it was recently shown that moderate to high levels of regular physical activity are associated with a reduced lung function decline and COPD risk among smokers [14]. Furthermore, in earlier reports regular exercise was noted to protect against diseases associated with chronic inflammation [15]. Inflammation is an important element in the pathogenesis of COPD. The contribution of PR for reduction of $\mathrm{FEV}_{1}$ decline adds an additional beneficial effect of pulmonary rehabilitation for COPD patients. $\mathrm{FEV}_{1}$ decline may serve as a predictor of risk death from COPD, and therefore PR should be considered as a disease modifier [16]. The improvement of endurance time and work noted in the

Table 2: Effect of pulmonary rehabilitation on cycle exercise performance and BMI

\begin{tabular}{|c|c|c|c|c|c|c|c|}
\hline & \multicolumn{3}{|c|}{ Control group } & \multicolumn{3}{|c|}{ Rehabilitation group } & \multirow[b]{2}{*}{ P-value } \\
\hline & Before & After I-year & After 3-years & Before & After I-year & After 3 years & \\
\hline Max. sustained cycle work, W & $32 \pm 11$ & $30 \pm 8$ & $28 \pm 8$ & $30 \pm 9$ & $76 \pm 22$ & $78 \pm 24$ & $<0.01$ \\
\hline Max. sustained cycle time, Min. & $5.8 \pm 0.9$ & $5.6 \pm 1.1$ & $5.8 \pm 1.1$ & $6 \pm 1.1$ & $12.6 \pm 4.4$ & $11.8 \pm 4$ & $<0.01$ \\
\hline BMI & $24.6 \pm 1.8$ & $24.4 \pm 2.2$ & $21.6 \pm 2.4^{*}$ & $24.2 \pm 1.9$ & $25.4 \pm 2$ & $25.1 \pm 2.2$ & $<0.05$ \\
\hline
\end{tabular}

Max. -maximum, $\mathrm{W}$-watts, min.-minutes, *- only 3 years was significant, BMI-body mass index 


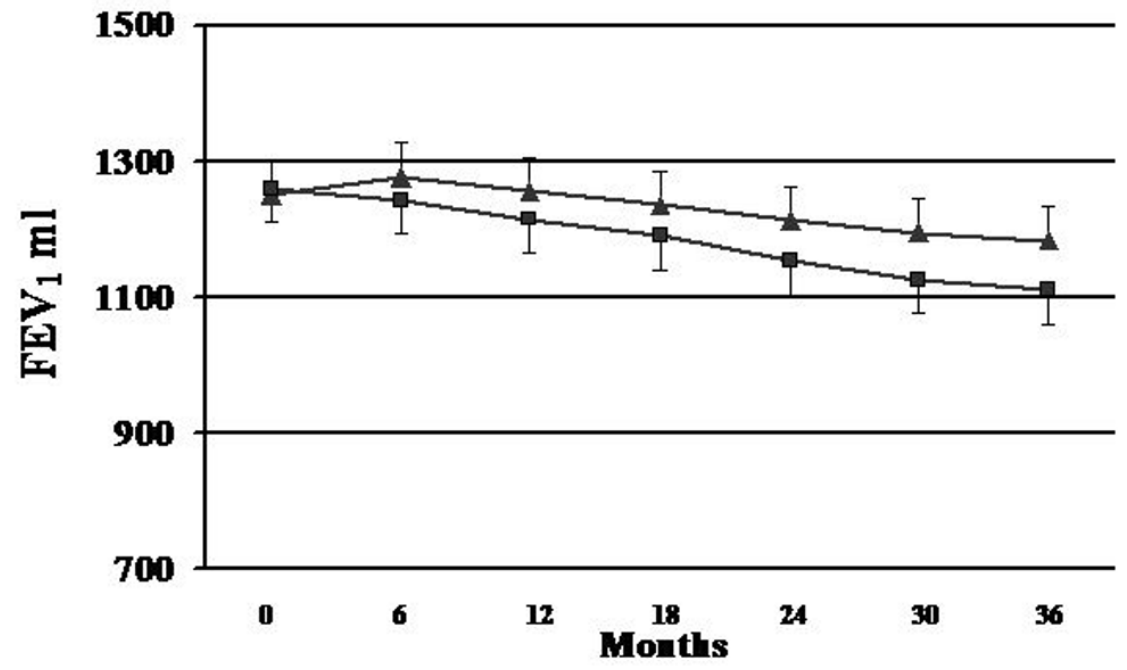

Figure I

Evolution of FEV, decline, rehabilitation group represented by line and black triangles, whereas control group by line and black squares. A significant difference in the rate of FEV, over time is noted between these two groups ( $<$ $0.001)$.

trial is consistent with previous reports [17]. One possibility no significant differences were noted regarding exacerbation-related hospitalizations in these two groups, may relate to the higher accessibility to medical care in the patients enrolled in our study, relative to the regular COPD patient. A randomized study would be preferable, in

Match study the control subjects who are 'matched' with the treated subjects on background covariates that the investigator believes need to be controlled [11]. Finally, since this study included patients with severe disease, the duration of three years to complete the study may have contributed to the relatively high number of dropouts (including death), for which we could not identify a specific reason.

\section{Conclusion}

Three years of pulmonary rehabilitation has an important beneficial impact on the rate of $\mathrm{FEV}_{1}$ decline, in addition to previously reported advantages of this treatment modality, for COPD patients.

\section{Competing interests}

The authors declare that they have no competing interests.

\section{Authors' contributions}

DS design the study, was responsible to the rehabilitation group and data analysis, and manuscript writing. MR participated in its design, data acquisition, coordination and drafted the manuscript IS was responsible to the matched control group, data acquisition and analysis, and reviewing manuscript.

\section{Acknowledgements}

The research was funded by the Tel Aviv Lung Association.

\section{References}

I. Rabe KR, Hurd S, Anzueto A, Barnes PJ, Buist SA, Calverley P, Fukuchi F, Jenkins C, Rodriguez-Roisin R, Weel CV, Zielinski J: Global strategy for the diagnosis, management, and prevention of chronic obstructive pulmonary disease: GOLD executive summary. Am J Respir Crit Care Med 2007, 176:532-55.

2. The Lung Health Study Research Group: Effect of inhaled triamcinolone on the decline in pulmonary function in chronic obstructive pulmonary disease. N EnglJ Med 2000, 343: I 902-92.

3. Burge PS, Calverley PM, Jones PW, Spencer S, Anderson JA, Maslen TK: Randomised, double blind placebo controlled study of fluticasone propionate in patients with moderate to severe chronic obstructive pulmonary disease: the ISOLDE trial. BMJ 2000, 320: I297-303.

4. Decramer M, Rutten-van Mölken M, Dekhuijzen PN, Troosters T, van Herwaarden C, Pellegrino R, van Schayck C, Olivieri D, Del Donno $\mathrm{M}$, De Backer W: Effects of $\mathbf{N}$-acetyl-cysteine on outcomes in chronic obstructive pulmonary disease (Bronchitis Randomized on NAC Cost-Utility Study, BRONCUS): a randomised placebo-controlled trial. Lancet 2005, 365: I552-60.

5. Fletcher $C$, Peto R: The natural history of chronic airflow obstruction. Br Med J I 977, I:1645-8.

6. Nici L, Donner C, Wouters E, Zuwallack R, Ambrosino N, Bourbeau J, Carone M, Celli B, Engelen M, Fahy B: American thoracic society/european respiratory society statement on pulmonary rehabilitation. Am J Respir Crit Care Med 2006, I 73(I 2): I390-I 4 I3.

7. Ries L, Bauldoff GS, Carlin BW, Casaburi R, Emery CF, Mahler DA, Make B, Rochester CL, ZuWallack R, Herrerias C: Pulmonary Rehabilitation, Joint ACCPIAACVPR Evidence-Based Clinical Practice Guidelines. CHEST 2007, 13 1:4S-42S.

8. Griffiths TL, Burr ML, Campbell IA, Lewis-Jenkins V, Mullins J, Shiels K, Turner-Lawlor PJ, Payne N, Newcombe RG, lonescu AA, Thomas 
J, Tunbridge J: Results at I year of outpatient multidisciplinary pulmonary rehabilitation: a randomised controlled trial. Lancet 2000, 355:362-68.

9. Troosters T, Gosselink R, Decramer M: Short- and Long-term Effects of Outpatient Rehabilitation in Patients with Chronic Obstructive Pulmonary Disease: A Randomized Trial. Am J Med 2000, 109:207-2I2.

10. Engstrom CP, Persson LO, Larsson S, Sullivan M: Long-term effects of a pulmonary rehabilitation programme in outpatients with chronic obstructive pulmonary disease: a randomized controlled study. Scand J Rehab Med 1999, 31:207-213.

II. D'Agostino RB: Propensity score methods for bias reduction in the comparison of a treatment to a non-randomized control group. Statist Med 1998, 17:2265-228I.

12. American Thoracic Society: Standardization of spirometry: 1994 update. Am J Respir Crit Care Med I 995, I 52: I 107-36.

13. American Thoracic Society/American College of Chest Physicians: ATS/ACCP statement on cardiopulmonary exercise testing. Am J Respir Crit Care Med 2003, 167:2 I I-277.

14. Garcia-Aymerich J, Lange P, Benet M, Schnohr P, Anto JM: Regular physical activity modifies smoking-related lung function decline and reduces risk of chronic obstructive pulmonary disease. Am J Respir Crit Care Med 2007, 175:458-463.

15. Petersen AM, Pedersen BK: The anti-inflammatory effect of exercise. J Appl Physiol 2005, 98: I I54-I I62.

16. Sircar K, Hnizdo E, Petsonk $E$, Attfield $M$ : Decline in lung function and mortality: implications for medical monitoring. Occup Environ Med 2007, 64:46I-466.

17. Laviolette L, Bourbeau J, Bernard S, Lacasse Y, Pepin V, Breton MJ, Baltzan M, Rouleau F, Maltais F: Assessing the impact of pulmonary rehabilitation on functional status in COPD. Thorax 2008, 63:II5-I2I.

\section{Pre-publication history}

The pre-publication history for this paper can be accessed here:

http://www.biomedcentral.com/1471-2466/9/26/prepub

Publish with Bio Med Central and every scientist can read your work free of charge

"BioMed Central will be the most significant development for disseminating the results of biomedical research in our lifetime."

Sir Paul Nurse, Cancer Research UK

Your research papers will be:

- available free of charge to the entire biomedical community

- peer reviewed and published immediately upon acceptance

- cited in PubMed and archived on PubMed Central

- yours - you keep the copyright
BioMedcentral 